\title{
BreEding for Disease Resistance IN FARM
}

ANIMALS, 2ND EDITION 



\section{BREEDING FOR DISEASE RESISTANCE IN FARM ANIMALS, 2ND EDITION}

Edited by

R.F.E. Axford

School of Agricultural and Forest Sciences University of Wales, Bangor UK

S.C. Bishop

Roslin Institute (Edinburgh)

Roslin

UK

F.W. Nicholas

Department of Animal Science University of Sydney, Sydney

Australia

J.B. Owen

School of Agricultural and Forest Sciences

University of Wales, Bangor 
$\mathrm{CABI}$ Publishing is a division of $\mathrm{CAB}$ International

CABI Publishing

CABI Publishing

$\mathrm{CAB}$ International

10 E 40th Street

Wallingford

Suite 3203

Oxon OX10 8DE

UK

New York, NY 10016

USA

Tel: +44 (0)1491 832111

Fax: +44 (0)1491 833508

Tel: +1 2124817018

Fax: +1 2126867993

Email: cabi@cabi.org

Email: cabi-nao@cabi.org

(c) $\mathrm{CAB}$ International 2000. All rights reserved. No part of this publication may be reproduced in any form or by any means, electronically, mechanically, by photocopying, recording or otherwise, without the prior permission of the copyright owners.

A catalogue record for this book is available from the British Library, London, UK.

\section{Library of Congress Cataloging-in-Publication Data}

Breeding for disease resistance in farm animals / edited by R.F.E.

Axford ... [et al.]. -- 2nd ed.

p. $\mathrm{cm}$.

Includes bibliographical references.

ISBN 0-85199-325-7 (alk. paper)

1. Livestock--Breeding. 2. Livestock--Genetics. 3. Veterinary

immunogenetics. I. Axford, R. F. E.

SF105.B696 1999

636.089'6079--dc21

99-27340

CIP

ISBN 0851993257

Typeset by Solidus (Bristol) Limited.

Printed and bound in the UK by Biddles Ltd, Guildford and King's Lynn. 


\section{Contents}

Introductory Editorial: Breeding for Disease Resistance in its

Evolutionary Context

1. DNA Markers, Genetic Maps and the Identification of QTL: General Principles

A.M. Crawford, K.G. Dodds and J.C. McEwan

2. Modelling Farm Animal Diseases S.C. Bishop and G. Gettinby

3. The Immune System M.J. Doenhoff

4. The Major Histocompatibility Complex and its Role in Disease Resistance and Immune Responsiveness M.F. Rothschild, L. Skow and S.J. Lamont

5. Rodent Models of Genetic Resistance to Parasitic Infections D. Wakelin

\section{Part II Parasites and Vectors}

6. Genetics of Helminth Resistance 
7. Host Resistance to Ticks and Tick-borne Diseases: Its Role in Integrated Control

B. Minjauw and J.J. de Castro

153

8. Genetic Aspects of Resistance to Ovine Cutaneous Myiasis H.W. Raadsma

9. Exploitation of Resistance to Trypanosomes and Trypanosomosis G.D.M. d'Ieteren, E. Authié, N. Wissocq and M. Murray

\section{Part III Bacteria}

10. Genetic Aspects of Resistance to Ovine Footrot H.W. Raadsma

11. Mastitis in Dairy Cattle J.B. Owen, R.F.E. Axford and S.C. Bishop

12. Escherichia coli and Salmonella Diarrhoea in Pigs I. Edfors-Lilja and P. Wallgren

\section{Part IV Viruses and Subviruses}

13. Viral Diseases K.A. Schat and C.J. Davies

14. Diseases Caused by Maedi-Visna and Other Ovine Lentiviruses J.C. DeMartini, A. de la Concha-Bermejillo, J.O. Carlson and R.A. Bowen

15. Transmissible Spongiform Encephalopathies N. Hunter

\section{Part V Production Diseases}

16. Genetics of Susceptibility in Cattle and Sheep C.A. Morris

17. Breeding for Resistance to Production Diseases in Poultry B.H. Thorp and E. Luiting

18. Genetic Aspects of Health and Disease Resistance in Pigs B.N. Wilkie and B.A. Mallard

19. Lameness

O. Distl 


\section{Contributors}

E. Authié, Programme Santé Animale, CIRAD-EMVT, BP5035, 34032 Montpellier Cedex 1, France

R.F.E. Axford, School of Agricultural and Forest Sciences, University of Wales, Bangor, Gwynedd LL57 2UW, UK

S.C. Bishop, Roslin Institute (Edinburgh), Roslin, Midlothian EH25 9PS, UK

R.A. Bowen, Department of Physiology, Colorado State University, Fort Collins, CO 80523, USA

J.O. Carlson, Department of Microbiology, Colorado State University, Fort Collins, CO 80523, USA

A.M. Crawford, AgResearch Molecular Biology Unit and Centre for Gene Research, University of Otago, PO Box 56, Dunedin, New Zealand

C.J. Davies, Department of Microbiology and Immunology, College of Veterinary Medicine, Cornell University, Ithaca, NY 14853, USA

J.J. de Castro, FAO Sub Regional Office, PO Box 3730, Harare, Zimbabwe

A. de la Concha-Bermejillo, Department of Pathobiology, Texas A\&M University, Texas Agricultural Experiment Station, San Angelo, TX 76901, USA

J.C. DeMartini, Department of Pathology, Colorado State University, Fort Collins, CO 80523, USA

O. Distl, Department of Animal Breeding and Genetics, School of Veterinary Medicine Hannover, PO Box 711180, 30545 Hannover, Germany

K.G. Dodds, AgResearch Invermay Agricultural Centre, Private Bag 50034, Mosgiel, New Zealand

M.J. Doenhoff, School of Biological Sciences, University of Wales, Bangor, Gwynedd LL57 2UW, UK

I. Edfors-Lilja, Department of Technology and Natural Sciences, University of Växjö, S-351 95, Växjö, Sweden

L.C. Gasbarre, USDA-ARS, LPSI, Immunology and Disease Resistance Laboratory, Beltsville Agricultural Research Center, Beltsville, MD 20705, USA

G. Gettinby, Department of Statistics and Modelling Science, University of 
Strathclyde, Livingstone Tower, 26 Richmond Street, Glasgow G1 1XH, UK

N. Hunter, Institute for Animal Health, Neuropathogenesis Unit, West Mains Road, Edinburgh EH9 3JF, UK

G.D.M. d'Ieteren, International Livestock Research Institute(ILRI), PO Box 30709, Nairobi, Kenya

S.J. Lamont, Department of Animal Science, Iowa State University, Ames, IA 50011, USA

E. Luiting, Roslin Institute (Edinburgh), Roslin, Midlothian EH25 9PS, UK

J.C. McEwan, AgResearch Invermay Agricultural Centre, Private Bag 50034, Mosgiel, New Zealand

B.A. Mallard, Department of Pathobiology, University of Guelph, Guelph, Ontario, Canada N1G 2W1

J.E. Miller, Department of Epidemiology and Community Health, School of Veterinary Medicine and Department of Animal Science, Louisiana Agricultural Experiment Station, Louisiana State University, Baton Rouge, LA 70803, USA

B. Minjauw, International Livestock Research Institute (ILRI), PO Box 30709, Nairobi, Kenya

C.A. Morris, Ruakura Agricultural Research Centre, Private Bag 3123, Hamilton, New Zealand

M. Murray, Department of Veterinary Clinical Studies, University of Glasgow Veterinary School, Bearsden, Glasgow G61 1QH, UK

F.W. Nicholas, Department of Animal Science, University of Sydney, Sydney, NSW 2006, Australia

J.B. Owen, School of Agricultural and Forest Sciences, University of Wales, Bangor, Gwynedd LL57 2UW, UK

H.W. Raadsma, Centre for Sheep Research and Extension, The University of Sydney, PMB 3, Camden, New South Wales, Australia

M.F. Rothschild, Department of Animal Science, Iowa State University, Ames, IA 50011, USA

K.A. Schat, Department of Microbiology and Immunology, College of Veterinary Medicine, Cornell University, Ithaca, NY 14853, USA

L. Skow, Department of Veterinary Anatomy and Public Health, Texas A\&M University, College Station, TX 77843, USA

B.H. Thorp, Ross Breeders Ltd, Newbridge, Midlothian EH28 8SZ, UK

D. Wakelin, School of Biological Sciences, University of Nottingham, University Park, Nottingham NG7 2RD, UK

P. Wallgren, National Veterinary Institute, S-750 07, Uppsala, Sweden

B.N. Wilkie, Department of Pathobiology, University of Guelph, Guelph, Ontario, Canada N1G 2W1

N. Wissocq, International Livestock Research Institute (ILRI), PO Box 30709, Nairobi, Kenya 


\section{Introductory Editorial: Breeding for Disease Resistance in its Evolutionary Context}

Present-day species of farm livestock have inherited a complex genome from their wild progenitors. Despite the bewildering proliferation of phenotypic variation in breeds within species, genetic structure studies indicate that genetic variation is much less than this would indicate and that genetic difference between extant breeds and their wild relatives is rather small (Rogdakis et al., 1995).

This conserved genome from pre-domestication evolution owes much to the co-evolution of livestock host and its parasitic pathogens. This strategy (Khibnik and Kondrashov, 1997) is a continual battle to achieve an ecological symbiotic equilibrium, optimal for the joint survival of the two species.

Breeding for disease resistance, the subject of this book, has much to do with trying to lessen the impact of ecological perturbations involved in modern pharmaceutical intervention. It is relevant to note that the fossil record suggests that environmental perturbations of various magnitude, such as the major event that may have resulted in the demise of the dinosaurs 65 million years ago, had significant consequences for the evolution of species. Many species have become extinct and others have been newly created by branching speciation. Sometimes explosive multiplication of hitherto rare species occurred, as in the Cambrian explosion (Morris, 1998).

At domestication, another major perturbation in a species' evolution, many animal progenitors would be expected to be near an optimum equilibrium with their pathogens under the prevailing environmental conditions (including stocking rate). In spite of many changes in the environment and in selection objectives following domestication, the wild animal can still be regarded as an informative template for modern livestock, particularly in the fitness and behaviour traits, including disease resistance. 


\section{After Domestication}

Fossil and other archaeological evidence, particularly inferences from the changes in skeletal features, suggest that domestication was initially a traumatic event for livestock species (Zeuner, 1963). Deterioration due to overstocking, resulting in poorer nutrition and greater parasite infection, probably accounts for the decreased skeletal size and changed conformation observed after domestication.

The new domesticates would have been subjected suddenly to novel conditions of severity and type of pathogen challenge, at a time when poorer nutrition would have reduced their acquired immunity.

However, domestication into nomadic/transhumant systems would have ameliorated some of the changes in conditions for newly domesticated pastoral species, particularly since the change in flock/herd movements might well have been minimally different from the seasonal movements of animals in the wild (Zeuner, 1963). As time went on there was the possibility, in the richer, more fertile areas, for domesticated farm livestock to enjoy improving conditions and optimal stocking rates. Indeed, some of the livestock kept by the present-day Bedouin nomads of the Middle East are amongst the best cared for animals anywhere in the world. Another instance of optimal care for stock seems to have been that under the Norfolk four-course rotation, with its sustainable fertility and its special provision of winter fodder as swedes, etc. This period of the late 19th and early 20th century in the UK, might well have been the golden age for domesticated livestock in terms of welfare and disease control.

\section{Latter Half of the 20th Century}

The advent of artificial nitrogen fertilizer in the 1930s and the subsequent development of intensive mechanized agriculture, caused a sea change in animal husbandry from the disease viewpoint, in developed Western countries. Highly intensive pig and poultry units developed, followed by an incipient trend towards a heavy stocking rate of land and buildings for the hitherto extensively managed pastoral ruminant species.

This development coincided with the discovery of penicillin, other antibiotics and the array of veterinary drugs which appeared to be the simple final answer, albeit expensive, to the disease problems of such intensive agriculture.

Evolutionary biology clearly indicated the inevitable outcome of such a strategy - the increase in frequency of genes for resistance, which is seen as the emergence of resistant strains of pathogens and parasites.

Figure I.1 illustrates the potential power of intense selection to target rare parasite genotypes, resistant to antiparasitic drugs. This is a simulation of a population of 5000 with a basal polygenic mean value 10 and SD 2.5 with 25 individuals carrying a single gene of values of $0.5,1,2$ or 3 times the basal SD. It indicates that at high selection intensity and major gene value $3 \times$ basal SD, the resistance gene becomes highly concentrated in the selected group. 


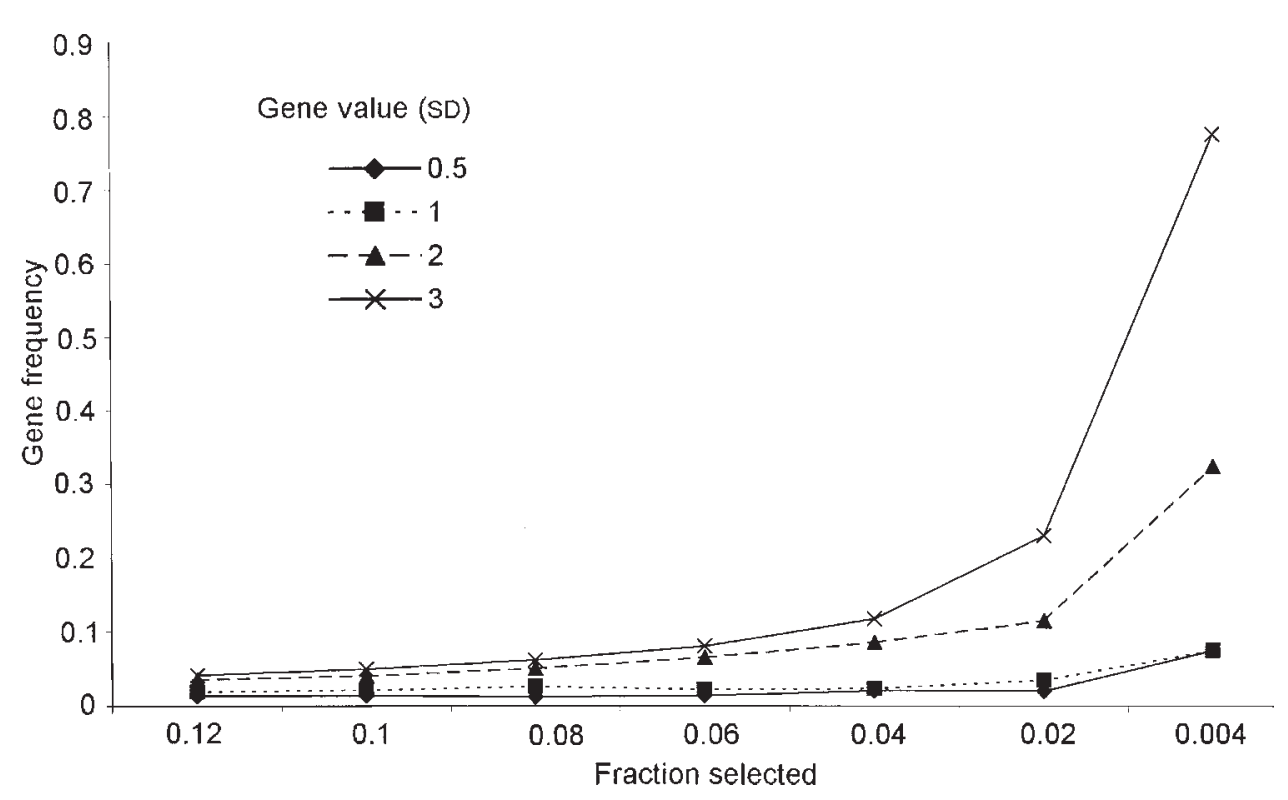

Fig. I.1. Effect of gene value (in SDS) and selection fraction on gene frequency.

A stochastic simulation of responses to selection in a multifactorial trait, such as disease resistance, was conducted by Owen et al. (1998), to examine the effect of perturbation, akin to the macro events before domestication, on pathogen ecology. Results from 15 generations of selection show that, under intense selection, nearly $100 \%$ of the total genetic response at some stages of selection can be accounted for by the increased frequency of a relevant major gene at a single locus, as opposed to the basal polygenic component which accounts for most of the response at more lax selection pressure (Fig. I.2).

It is interesting to see that the indications from this simulation are borne out by a study of the genetic control of domestication effects in the common bean (Koinange et al., 1996).

Thus 'manufacturers' recommended dose rates for antiparasitic drugs, while clearly efficacious in killing the parasites in the short term, seem bound to accelerate the development of parasite resistance in the longer term, through the intense selection pressure exerted.

The initial forms of the resistant pathogens would be expected to be less potent than the 'wild' forms because of the selection emphasis on drug resistance. However, Bjorkman et al. (1998) have demonstrated that potency is quickly recovered and there are several instances of the subsequent emergence of super-pathogens that are more lethal and difficult to control than their predecessors.

Epistatic interaction is likely to set up a network of interactive changes in the genome arising from the emergence of a single gene for resistance. One of the resulting wonders of the genome is the wealth of dormant major genes (whether recessives or genes inhibited by the epistatic action of restrictor alleles at other loci) that lie in wait for an environmental change that fosters 


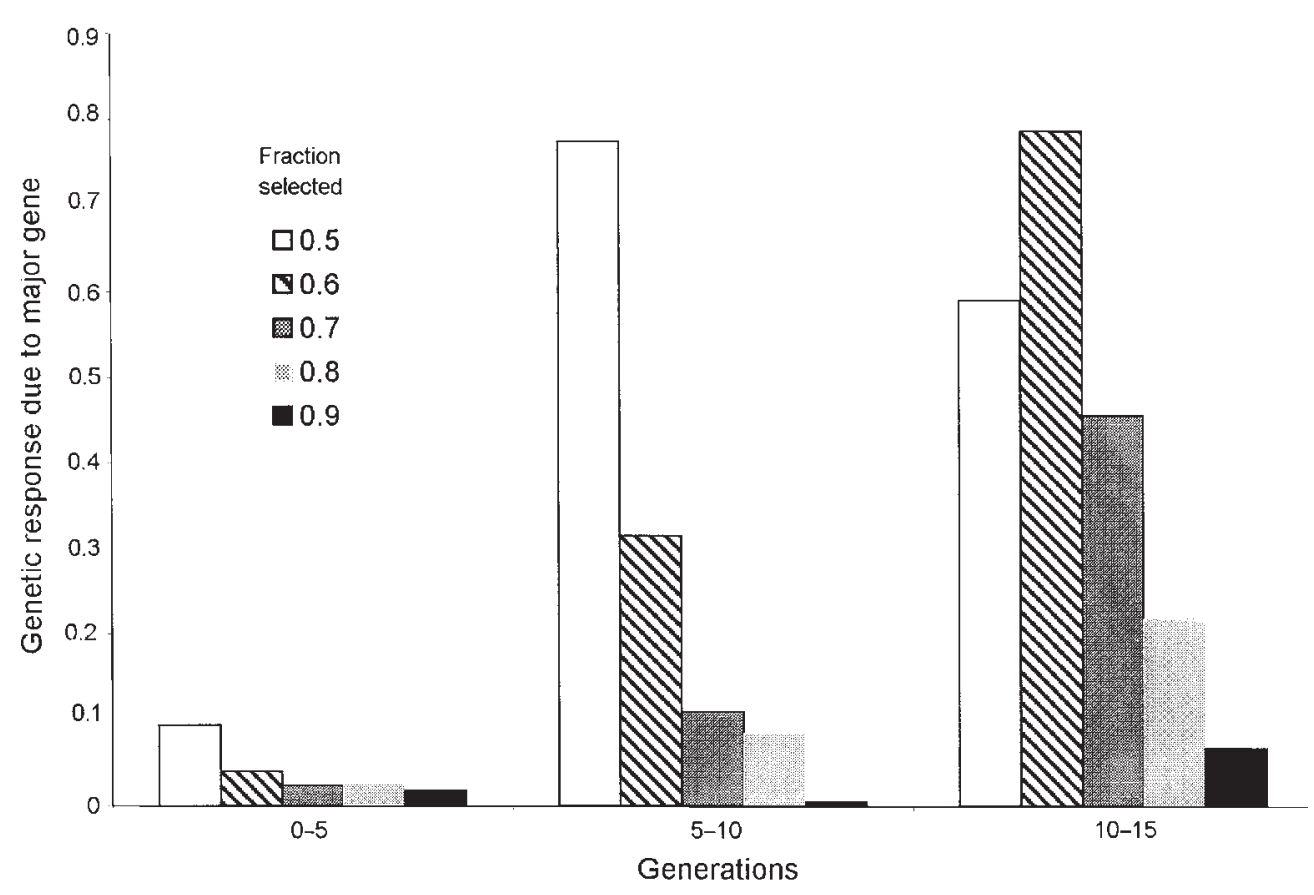

Fig. I.2. Effect of fraction selected on the proportion of total genetic response due to major gene frequency changes in generations $0-5,5-10,10-15$ with basal $h^{2}=0.4$.

their overt emergence. A similar biological phenomenon (albeit in a different context) has been seen in the 'emergence' of major genes affecting production traits in farm animals, where selection for particular traits has resulted in high frequencies of particular alleles at the halothane locus in pigs, the doublemuscling locus in cattle and the callipyge locus in sheep.

\section{Future Strategy}

Emphasis on breeding for disease resistance stems partly from awareness of the development of pathogen resistance to the therapeutic agent, which has led to calls for reduction in the use of antibiotics and other drugs throughout human and animal medicine. This emphasis is doubly important because of the possibility of between-species transfer of such resistance, particularly from livestock pathogens to human pathogens. However, in the rich democracies this is easier said than done. Medical GPs are struggling with the insistent right of mothers for their children to be given antibiotics even for mild viral colds. The large multinational pharmaceutical companies have evolved to meet just such a consumer demand, which may unwittingly turn out to have an uncontrollable suicidal will of its own. 
Various options for future action need urgent consideration.

1. Therapeutic intervention. In view of the primacy of evolutionary shorttermism over the predictions and avowed planning intentions of individuals and organizations hitherto, it may be considered prudent not to dismiss the possibility that the free rein of scientific ingenuity and commercial pressures may come up with similar novel solutions that abound in nature as a result of the similar simple genetic algorithm of evolution.

One such approach to therapy, which has had considerable attention in the field of pest control, especially in crop plants, is that of biological control. The difficulty of predicting its consequences in the complex ecological context of its projected use has led to unforseen difficulties in the past and considerably proscribes its usefulness in many applications. While, as yet, it may not have direct relevance to breeding for disease resistance, a recent development in this field, which holds out considerable promise to combat the difficulties alluded to with antibiotic use, is the use of bacteriophages. Barrow et al. (1998) have indicated the possibility of such an approach for the therapy of Escherichia coli septicaemia and meningitis in chickens and calves. There are also reports of its successful application to supplant antibiotics in human medicine (Morris, 1998). A merit of this approach is that it is strictly targeted to its quarry bacterium, rather than catholic in its appetite, as are the antibiotics. It also seems at present to be more difficult for bacteria to resist bacteriophages by their existing mechanisms.

2. Avoidance or reduction in the need for therapy. In animal disease control a moderate alternative is possible. This involves reduction of challenge by using lower stocking rates, thus allowing less frequent strategic drug intervention to control parasitic pathogens. In its extreme this could approximate the 'organic' approach.

3. Any of these and other viable future strategies may be replaced or considerably aided by various facets of breeding for disease resistance in our farm animals, as discussed in this book. This encompasses selection pressure within conventional breeding schemes on general immunological competence as well as on targeted resistance tests for specific major pathogens. This approach may result in a polygenic response as well as an increased frequency of favourable major genes.

In this respect an exciting potential exists for marker-assisted selection (MAS) acting on relevant candidate functional genes, or on DNA markers closely linked to quantitative trait loci (QTL). The immense investment in human genome mapping is likely to accelerate progress in the farm livestock mapping effort over the next few decades. The denser the maps available, the more likely it is that useful practical developments can occur at farm level, similar to that of the control of Marek's disease in poultry.

To what extent these approaches can reset the co-evolutionary oscillation between pests and pathogens at a lower level and enable the human population to be adequately fed on traditional plant and animal organisms remains to be seen. 
This book examines these issues and the current state of play, in order to stimulate further thinking and cooperation in trying to solve one of mankind's difficult challenges. Since the first edition (1991) there has been a fruitful decade of research in breeding for disease resistance, and the present book aims to encapture and systemize these advances as a convenience to a widening spectrum of workers and students with interest in the subject. Some of the chapters remain with virtually the same titles and mainly update the reader on current developments. Other subjects, because of changes in emphasis over the decade, have been reclassified and do not have identical counterparts in the previous book. Still other chapter areas have been omitted because other fields have advanced relatively faster over the decade and therefore have been given priority.

\section{References}

Barrow, P., Lovell, M. and Berchieri, A. (1998) Use of lytic bacteriophage for control of experimental Escherichia coli septicaemia and meningitis in chickens and calves. Clinical and Diagnostic Laboratory Immunology 5, 294-298.

Bjorkman, J., Hughes, D. and Andersson, D.I. (1998) Virulence of antibiotic-resistant Salmonella typhimurium. Proceedings of the National Academy of Science USA 95, 3949-3953.

Khibnik, A.I. and Kondrashov, A.S. (1997) Three mechanisms of Red Queen dynamics. Proceedings of The Royal Society of London Series B - Biological Sciences 264 (1384), 1049-1056.

Koinange, E.M.K., Singh, S.P. and Gepts, P. (1996) Genetic control of the domestication syndrome in common bean. Crop Science 36, 1037-1045.

Morris, M. (1998) The virus that cures. Biologist 45(5), 196 (letter).

Owen, J.B., Ap Dewi, I. and Roberts, D. (1998) The effect of intensity of selection on the response to selection in the presence of a major gene and an underlying additive polygenic component. Proceedings of the 6th World Congress on Genetics Applied to Livestock Production. Armidale, Australia. January 1998 26, 21-24.

Morris, S.C. (1998) The evolution of diversity in ancient ecosystems: a review. Philosophical Transactions of The Royal Society of London Series B - Biological Sciences 353 (1366), 327-345.

Rogdakis, E., Kutsuli, P., Surdis, I. and Panopulu, E. (1995) Genetic-structure of Greek sheep breeds. Journal of Animal Breeding and Genetics - Zeitschrift fur Tierzuchtung und Zuchtungsbiologie 112(4), 255-266.

Zeuner, F.G. (1963) A History of Domesticated Animals. Hutchinson, London. 


\title{
DNA Markers, Genetic Maps and the Identification of QTL: General Principles
}

\author{
A.M. Crawford ${ }^{1}$, K.G. Dodds ${ }^{2}$ and J.C. McEwan ${ }^{2}$ \\ ${ }^{1}$ AgResearch Molecular Biology Unit and Centre for Gene \\ Research, University of Otago, Dunedin, New Zealand; \\ ${ }^{2}$ AgResearch Invermay Agricultural Centre, Mosgiel, New Zealand
}

\section{Summary}

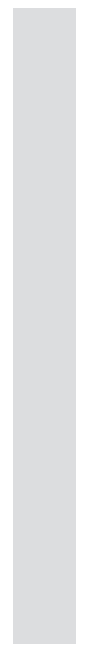

\begin{abstract}
Efficient quantitative trait loci (QTL) detection and identification methods in farm animals rely on the availability of numerous, cheap mapped polymorphic DNA markers, which preferably can also be linked comparatively to the better-mapped human and mouse genomes. There is still some way to go before this situation can be achieved in most farmed species, but sufficient markers exist to commence genomic scanning experiments for disease traits. We envision that QTL detection and identification will use a wide variety of techniques, each appropriate to its specific situation. Where possible, preliminary screens based on complex segregation analysis will identify segregating QTL, which will then be identified to a specific genomic region using some form of appropriate genomic screening. This will be followed by independent validation and finer mapping using a combination of techniques. Two logical end-points then exist, identification of the actual locus or marker-assisted selection (Meuwissen and Goddard, 1997). The latter is probably more cost effective in the near future and is particularly suited for difficult-to-measure traits such as disease resistance.
\end{abstract}

\section{Introduction}

Primary linkage maps covering all chromosomes are now available for all the major domestic livestock species and most research today is not concerned with map generation per se but the use of markers on these maps to search for regions of the genome containing loci affecting traits of economic importance. This process has become known as a search for quantitative trait loci (QTL) or, more recently, a genome scan. This chapter reviews the methodologies that led to the development of genetic linkage maps and genome scans. First, various commonly used DNA marker technologies are described, with 
particular emphasis placed on describing their relative strengths and weaknesses. Then DNA mapping techniques are examined, followed by discussion on QTL identification and localization methods relevant to the study of disease traits in farmed livestock.

\section{DNA Markers}

From the time of Mendel until the 1980s the only single-locus genetic markers available to geneticists were either simple phenotype markers, such as eye colour in Drosophila, or protein polymorphisms, such as the haemoglobin blood groups. Using these markers, some quite detailed genetic linkage maps were developed for model species such as mice and Drosophila, but there were great limitations for linkage map construction in outbred livestock species. The advent of recombinant DNA technologies, in particular the polymerase chain reaction $(\mathrm{PCR})$ technique, suddenly removed the obstacle of marker availability so that linkage mapping projects for any species could be planned and implemented. This section details the numerous DNA marker types that have been developed over the past decade and describes their relative advantages and disadvantages for QTL searches, comparative linkage mapping and the measurement of genetic diversity.

\section{Multilocus markers}

Minisatellite or VNTR (variable number tandem repeat) markers

The minisatellites were the first tandem repeat markers with multiple alleles to be developed. Discovered by Jeffreys et al. (1985), they were the first markers to be sufficiently informative to reveal a unique genotype in each individual. With the advent of microsatellites they have fallen out of favour for linkage studies because they are technically demanding and require a large quantity of DNA for analysis. They were mostly dominant markers with only one identifiable allele. Minisatellites were also located mainly in telomeric regions so that good coverage of the genome using these markers could not be achieved.

A few highly informative single-loci minisatellites were identified in livestock (Georges et al., 1990) and these have been found useful. The first marker linked to the callipyge gene of sheep was a single-locus minisatellite (Cockett et al., 1994).

\section{RAPD (random amplified polymorphic DNA fragments) markers}

These were one of the first PCR-based markers to be used (Williams et al., 1990). Small primers (8-10 bp) were used to amplify a mixture of random fragments of DNA from the genome. The size of the primers was set such that about 20 bands were amplified by each PCR reaction. Some of these bands would be polymorphic and could be used as genetic markers. These markers have the great advantage of being very easily generated and requiring only small quantities of DNA. For this reason many linkage maps, especially in 
plants, have used RAPD markers. Since heterozygous and homozygous individuals cannot be differentiated, the markers are dominant. The appearance (and disappearance) of bands is very sensitive to slight changes in PCR conditions, so that RAPD markers are not easily reproducible. The most serious disadvantage, however, is that a new map must be generated for each new pedigree being examined, as there is no locus specificity in the primers used. The bands generated by a particular primer in one pedigree may not bear any relation to bands generated by the same primer in a second pedigree.

\section{AFLP (amplified fragment length polymorphisms) markers}

These are now the multilocus markers of choice (Vos et al., 1995). Genomic DNA is cut with restriction endonucleases and linkers are ligated to each end of the restriction fragments. Selective PCR primers are then used to amplify subsets of fragments from the mixture of genomic restriction fragments. The selective primers encompass the linkers added on to the end of the restriction fragments and include additional bases to the 3' end of the primer to give additional specificity. The amplified fragments are then separated according to size. Those bands that are present in some individuals but absent in others can be used as genetic markers.

These markers have the same advantage as RAPD, being easily generated, but they are much less reliant on PCR conditions staying exactly the same in order to obtain reproducible amplification products. To obtain a new set of markers, small changes in the 3 ' bases of the amplifying primers are all that is required, so this technology can provide a limitless supply of new markers. The markers have the disadvantages of being dominant, requiring the generation of a new map for each new set of pedigrees being studied.

\section{Single-locus markers}

\section{Restriction fragment length polymorphisms (RFLPs)}

These, the first DNA markers developed, predate the development of PCR methods. The RFLP method utilizes restriction endonuclease digestion of genomic DNA, its separation by size using agarose gel electrophoresis, and detection and analysis of the DNA sequence by Southern blotting. The RFLP marker detects the presence or absence of a restriction site. A very full description is found in Sambrook et al. (1989).

RFLP markers are codominant. The example shown in Fig. 1.1 is the simplest case. Here a large fragment of DNA (allele A) has a point mutation in a restriction site such that it will sometimes be cut into two pieces by the enzyme EcoRI. Other times it will stay intact. In this particular case, only one of the two fragments (allele $\mathrm{B}$ ) produced by restricting the A allele can be detected. The other fragment will probably have run off the gel. The enzymes most likely to give an RFLP marker in ruminants are MspI and TaqI (Montgomery et al., 1995). The two major disadvantages of these markers are that they are technically demanding and require large quantities of DNA (approximately $5 \mu \mathrm{g}$ per lane, compared with $1 \mathrm{ng}$ for any PCR-based test). 


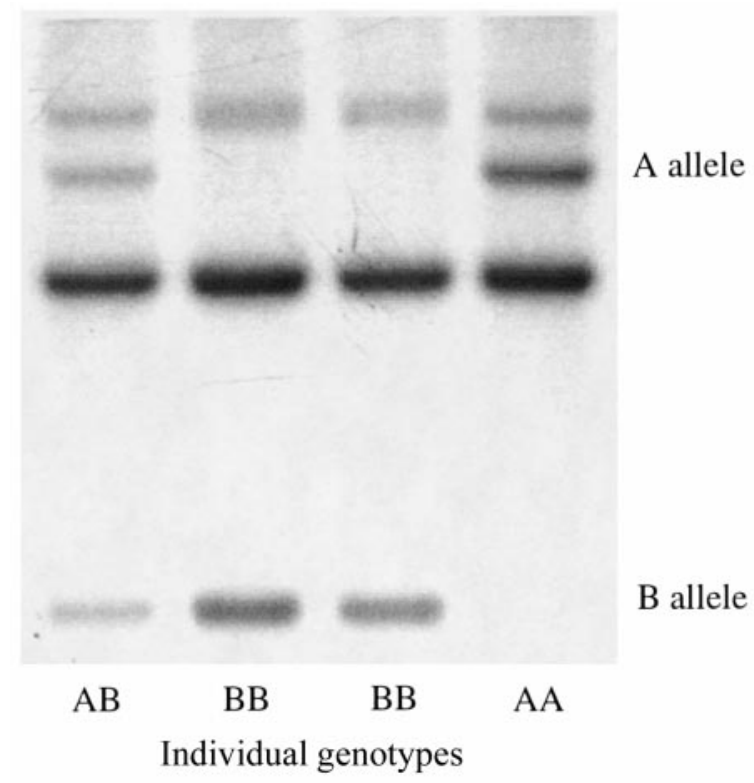

Fig. 1.1. The result of an RFLP analysis of sheep genomic DNA from four animals, digested with EcoRI. (Kindly supplied by Dr S.H. Phua.)

\section{Microsatellites}

Microsatellites are the markers responsible for the recent expansion in genetic linkage maps of farm animals (see p. 13 and Table 1.1). Like the minisatellites, they are multiallelic tandem repeats. However, they are single-locus, codominant, spread throughout the genome, require only small amounts of template DNA and are relatively easy to find and characterize.

At the heart of any microsatellite is a simple sequence, either a mono-, di-, tri- or tetranucleotide, that is repeated between 10 and 50 times. Virtually all of the microsatellites that have been found for livestock have the sequence (AC/GT) as the repeat unit. The reason for this is not that the other types do not exist but that this type is the most abundant within the livestock genomes and hence is much easier to find and characterize. The variation between alleles of the microsatellites is due to variation in the number of simple sequence repeats. Microsatellites are typed by designing primers to the unique DNA sequences on either side of the repeat and, using PCR, amplifying the region containing the repeat. The size of the PCR product is then measured, usually by electrophoresis on a DNA sequencing gel. Alleles differ in size according to the difference in number of simple-sequence repeats (Fig. 1.2).

\section{Single nucleotide polymorphisms (SNPs)}

The remaining variation found within the genome of animals occurs as changes in single nucleotides. The RFLP, the first DNA marker developed for eukaryotes, detects the variations that occur within a restriction endonuclease 


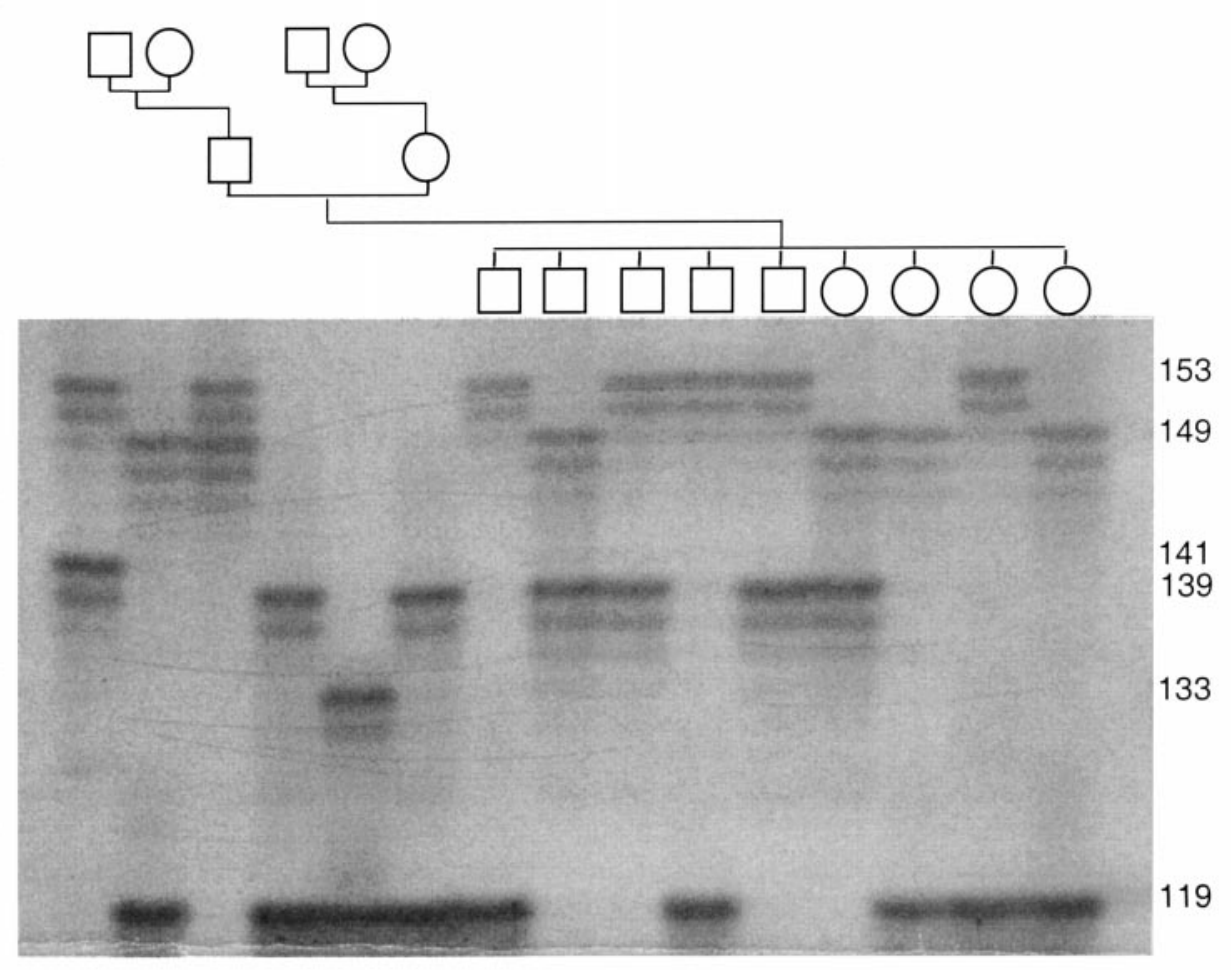

Fig. 1.2. Analysis of a three-generation pedigree of sheep with the microsatellite marker OarFCB226. A total of six different alleles can be identified in this family. The size of the different alleles, which range from 119 to 155 base pairs, is shown at the right side of the autoradiogram. The structure of the three-generation pedigree is shown at the top of the figure.

cut site. This, however, is only a small subset of all the polymorphic nucleotides in the genome. Very few of the nucleotide changes have any deleterious effect, so the preferred name is single nucleotide polymorphisms (SNPs) rather than point mutations. It has been estimated that an SNP occurs about once every kilobase of unique sequence in humans (Cooper et al., 1985). In other mammals, such as livestock, the figure is likely to be similar, so at least two to three million SNPs remain to be identified and characterized in any livestock species. SNPs represent by far the richest source of genetic variation available for research purposes.

With the advent of PCR any unique region of DNA could be amplified and scanned for variation in its DNA sequence. These SNPs can be detected in numerous ways. Once detected and characterized a wide variety of systems is now available for typing SNPs.

If SNPs occur at sufficiently high density, such as the hypervariable exon 2 region of $D R B$ and $D Q B$ genes, direct sequencing of the DNA can be a costeffective method of typing. More often, however, SNPs are hundreds of base 
pairs from their nearest neighbour, which means that other methods of detection are employed.

A base change in a short (approximately $100 \mathrm{bp}$ ) amplified fragment of DNA will often change the secondary structure of the DNA when it is melted and allowed to reanneal as single strands (Orita et al., 1989). The differences in secondary structure can be detected by electrophoresis on non-denaturing polyacrylamide gels, where one structure travels at a different speed through the gel. Ion gradients, gel density gradients and strictly controlled gel temperature have all been found useful in resolving these differences in secondary structure. The different methods of band resolution have led to many different acronyms, but the most commonly used name for this methodology is singlestranded conformational polymorphism (SSCP).

If the DNA sequence around the SNP is known, a number of typing methods become available. The most simple is that of Zhu and Clarke (1996). Four primers are designed. Two primers amplify the region containing the point mutation. Two further primers are designed such that their 3' ends correspond to one of the bases at the SNP. Depending on which primer was present in the reaction and which mutation(s) were in the template DNA, a smaller band would or would not be amplified. In this way, two PCR reactions can be used to type the SNP.

The invention of the 'Taqman' system of typing (Holland et al., 1991) allows typing of SNP markers without needing an electrophoresis step. Instead, the different alleles are detected by a change in the colour of the PCR reaction. Using a fluorogenic probe complementary for the target DNA sequences being amplified, the system detects and quantifies cycle by cycle increases in the level of PCR products. The probe consists of an oligonucleotide with a reporter and quencher dye attached. Uncoupling of the two dyes occurs when the probe, bound to the internal sequence of the PCR product, is cleaved by the nucleolytic activity of the Taq polymerase, which results in an increase in the fluorescence intensity of the reporter dye.

For SNP analysis, competition between oligonucleotides differing only at the point mutation is used. The two allele-specific oligonucleotides, which differ only by one base-pair change, are labelled with different dyes. Binding of the 'correct' oligonucleotide is detected by increased fluorescence dye used to label the 'correct' oligonucleotide. With a heterozygote, a mixture of the two dyes is released and detected. This method should reduce both the cost and time required to type SNPs.

The recent development of 'DNA chips' containing high-density arrays of DNA (Chee et al., 1996) may speed up the analysis process even further. Perhaps now is the time to begin searching for more SNPs in livestock, so that a large battery of SNPs is available when these new technologies become available.

\section{Genetic Mapping}

Genetic maps are sets of loci arranged in order and separated by distances (in units depending on the type of map), with each set corresponding to a 
chromosome pair. Locating genes of interest by scanning the genome in a linkage study is best conducted using a set of markers evenly spaced throughout the genome. These may be chosen from a marker map. Once linkage has been established, these and other types of maps help refine the location. Maps of genes or expressed sequences may provide clues to an effect's cause. Maps are also useful in selecting markers for other uses, such as population studies, tracking the inheritance of DNA segments using flanking markers, and parentage identification.

\section{Linkage maps}

This section discusses the construction of linkage maps. Ott's book (1991) on linkage analysis in humans is largely applicable to linkage studies in farmed animals, although there are some aspects particular to farmed animals.

\section{Genetic linkage}

Under Mendelian laws of segregation, loci on different chromosomes segregate independently. Loci on the same chromosome may show evidence of cosegregation, i.e. alleles passed to progeny are often of the same grandparental origin. The proportion of times that alleles are not of the same grandparental origin is the recombination fraction (rf). This statistical measure of the distance between a pair of loci ranges from 0 for tightly linked loci to 0.5 for loci that are far apart or on different chromosomes. The knowledge of which alleles of a parent came from which grandparent is termed the 'phase'.

\section{Populations useful for developing linkage maps}

A mapping population needs to provide information on the transmission of alleles from grandparents to progeny. Grandparental genotypes are not necessary for families of at least two in size, as some phase information can be inferred. The construction of linkage maps can be made more efficient by using appropriately designed populations. Optimal designs for livestock maps have been considered by Hetzel (1991), van der Beek and van Arendonk (1993) and Elsen et al. (1994). For a fixed total size, increasing family size will decrease the proportion of parents that need to be genotyped. There is a risk, particularly with a single family, that a locus may not be heterozygous (and so potentially informative for mapping) but could have been useful for applications of the map. However, the increased efficiency and precision of map distances more than compensates for the loss of such information, which can also be offset by the development of new markers. Full-sib families are useful for obtaining linkage information for both male and female meioses, further decreasing the proportion of parents genotyped per meiosis, and allowing mapping of the homogametic sex chromosome. Although genotype information on grandparents results in less reliance on inferring phase, additional progeny also helps establish phase.

In some farmed animal species, such as sheep and cattle, large paternal half-sib pedigrees are common. These can be used for mapping studies, rather 
than expensive, large, full-sib families. In these cases, however, there is no information on female meioses, including X-linkage. There is usually little information to be gained from genotyping the dams (Dodds et al., 1993; Elsen et al., 1994).

The efficiency of mapping is improved by the use of highly polymorphic markers. Another strategy to increase the informativeness of families is to use breed or subspecies crosses, since the most prevalent alleles may be different in different breeds. Breed crosses are therefore more likely to be heterozygous. Using a cross with grandparents of at least three different breeds (but with each parent being a breed cross) would maximize the chance of informative meioses under this scenario. This strategy has been particularly successful in deer and chickens.

The construction of rudimentary maps does not require large populations. Linkage at a true rf of 0.2 can be established with $90 \%$ power when there are 60-70 coinformative meioses in a few families. Using highly polymorphic markers results in up to $50 \%$ of meioses being coinformative. In practice a few half-sib families with 150-200 total progeny should be adequate. In this size of population there is a $90 \%$ chance of observing a recombination between two loci if the true rf between them is 0.05 . Ordering loci on a finer scale will therefore require larger mapping populations.

\section{Linkage between pairs of markers}

When the phase is known, the rf can be established simply as the proportion of recombinants to total informative meioses. When phase is not known (as is usually the case), likelihood methods are used to estimate the rf. Geneticists have traditionally presented such results as a lod score, the $\log _{10}$ of the ratio of the likelihood maximized with respect to the estimate of $\mathrm{rf}$, to that with the rf set to 0.5. A general algorithm for calculating likelihoods on pedigrees was published by Elston and Stewart (1971) and has since been extended to more complicated pedigree types. This algorithm forms the basis of linkage programs for general pedigrees such as LINKAGE (Lathrop et al., 1984) and MENDEL (Lange et al., 1988), and also for ANIMAP (Nielsen et al., 1995) which is designed for half-sib pedigrees. The algorithm involves calculating the likelihood for every possible combination of genotypes. The number of combinations gets large quickly if there are many individuals with unknown genotypes. CRI-MAP (Lander and Green, 1987) uses a simpler algorithm in that it fills in unknown genotypes only where they can be deduced. MAPMAKER (Lander et al., 1987) has been designed to handle crosses between inbred lines rather than general pedigrees. For some pedigree structures it may be possible to code the data in such a way that an analysis similar to that given by CRI-MAP can be obtained.

If a founder has a missing genotype, then the Elston-Stewart algorithm uses allele frequencies to assign probabilities to the various possible genotypes for that individual. This requires suitable estimates of the allele frequencies relevant to the ungenotyped founders. Allele frequencies can be estimated from pedigree data, or simultaneously estimated during linkage analysis (Boehnke, 1991; Dodds et al., 1993). For half-sib families, estimates based on counts of unambiguous alleles passed by the dams can give misleading results, 
but maximum likelihood estimates can be obtained by ignoring the major genotype in equations (3) and (4) of Dodds et al. (1993). The usefulness of incorporating information from allele frequencies decreases as the locus increases in polymorphism, but the computing requirements increase.

The rf may vary according to specific factors, such as the sex of the parent in which a meiosis is recorded, or the family in the experiment. Allowing a single value gives estimates of the sex-averaged $\mathrm{rf}$ (which will depend on the number of informative male and female meioses in the data). In some cases it is possible to allow for separate male and female rates by including both parameters in the likelihood model. For human autosomes, the female map is about $90 \%$ longer than the male map, but this relationship does not appear to be universal, with an estimated increase of 30\% in pigs (Archibald et al., 1995) and less than 5\% in cattle (Barendse et al., 1997; Kappes et al., 1997). A special case of allowing sex-specific rates is that of sex-linked loci.

Since mapping involves comparing a particular locus with many others, a stringent threshold must be set. A commonly used threshold, developed in the context of human linkage but suitable for other species with similar genome sizes, is a lod score of 3 (Ott, 1991). This ensures a less than 5\% chance of a marker showing significant linkage to a marker on a different chromosome. If an analysis of autosomal loci uses sex-specific recombination rates, the threshold should be increased by 0.3 to accommodate the extra degree of freedom.

\section{Assigning loci to linkage groups}

Assignment to linkage groups uses the linkage results for each pair of markers (two-point analyses) using a strategy such as the following:

1. Placing the first locus into a linkage group.

2. Adding any loci to the group that are linked to the first locus.

3. Adding any other loci to the group that are linked to any other locus in that group.

4. Taking the set of unassigned loci and repeating 1 to 3 until no unassigned loci remain.

Usually a more stringent threshold (e.g. lod $=4$ and $\mathrm{rf}<0.3$ ) than that used to declare two-point linkage is used to prevent false linkage erroneously joining linkage groups from different chromosomes. Providing such errors are not too common, they will usually become evident when trying to order the loci.

\section{Ordering sets of loci}

For a group of $m$ loci, a comparison of likelihoods will indicate which order is the most likely, and how well supported that order is. Many linkage packages can calculate likelihoods, maximized over interloci distances, for a given order, by extending the two-point methodology. CRI-MAP is often chosen for such analyses when highly polymorphic markers are used, because it has lower computing requirements and disregards only a small amount of the information in the data.

The number of possible orders, $m ! / 2$, increases rapidly with $m$, so that a 
comparison of all possible orders is generally not feasible. Algorithms have been devised to construct maps without evaluating all possible orders. Although these are not guaranteed to find the most likely order, they tend to work well in practice.

One such algorithm starts with a pair of loci (ideally highly informative and with $\mathrm{rf} \sim 0.2$ ), and then tries adding one locus at a time in such a way that the best supported order for the placement of the new locus is at least 1000 times more likely (support for the order of lod 3) than any other. The criterion for support for the order may need to be relaxed after initially adding as many loci as possible, to allow all other loci to be added to the map.

Another strategy is to obtain an approximate order using a simple method, and then comparing likelihoods of this order with perturbed orders (e.g. by transposing the order of each pair of adjacent loci, or by looking at all possible orders with permutations of each set of $n$ adjacent loci). Any order which has a higher likelihood than the current working order becomes the new working order. Several methods are available for obtaining an initial order - minimize the sum of adjacent rfs; maximize the sum of adjacent lod scores; and multidimensional scaling methods which collapse a set of distances in $m-$ 1 dimensions to a set in one dimension.

Over short regions it is reasonable to assume that multiple recombinants do not occur. For dense maps, loci may be ordered by requiring no close multiple recombinants. If two alleles passed by an individual come from different grandparents, there has been a recombination event; all those from one grandparent are at one end of the group, those from the other grandparent are at the other end. Continuing with each meiosis will allow these groups to be subdivided further. If there has been recombination in each interval, all the loci can be ordered by this method.

\section{Estimating distances between loci}

Distance estimates arise from maximizing the likelihood with respect to the distances between the loci. An increased complexity from the two-point case is the need to consider how distances between adjacent pairs of loci combine to give a distance between the outer pair of loci. This is done with the aid of mapping functions which transform rfs to a scale that is additive. Linkage packages commonly use either the Haldane or Kosambi map functions. The Haldane map function assumes that there is no interference (i.e. recombination occurs independently in adjacent intervals). The Kosambi map function models interference as high over short distances, but decreasing with distance. The unit for genetic distance, expressed by a map function, is a Morgan; distances are often specified in centimorgans (cM) giving the distances multiplied by 100 .

\section{Data checking}

Genotyping and other errors may be present in linkage datasets. Such errors can have a large effect on the results (e.g. a 1\% error between tightly linked loci will increase the estimated distance between them by $\sim 1 \mathrm{cM})$. These errors often reveal themselves through inconsistencies or unlikely events in maps, 
such as: (i) apparent pedigree inconsistency; (ii) unusual segregation ratios; (iii) multiple recombination over short distances; (iv) family differences in recombination rates; and (v) inflation of overall map length by insertion of a new locus. Mapping projects need to make these checks to reduce map errors.

\section{Presentation of maps}

Linkage maps are generally presented as scaled linear structures with positions of loci denoted. In some cases, different fonts are used to denote different types of markers. Sometimes a comprehensive map (including all loci) is given. In other cases a framework map, in which orders are supported by a lod $>3$, is given, with the positions of the additional loci denoted alongside, either as a best estimate, or as the intervals that attain a threshold likelihood relative to the best position estimate (e.g. lod 3 support).

Maps of farm animals

Some recent maps of farm animals are listed in Table 1.1. The pig and cattle maps are estimated to cover $99 \%$ of the genome, while those for sheep and chicken cover $90-95 \%$ of the genome. These estimates provide only a rough guide of the coverage, since estimates of total genome length are not very reliable, and estimated map lengths tend to be biased upward by genotyping errors. These genetic linkage maps consist primarily of microsatellite markers with a smaller number of RFLPs based on known genes. Microsatellite-based maps of man and mice each contain between 5000 and 10,000 microsatellites. The densest livestock map is that for cattle with 1300 microsatellites, but most current livestock species have at least 200 markers. Maps for pig, chicken, deer, sheep, and cattle can be found at http://www.ri.bbsrc.ac.uk./ genome_mapping.html.

\section{Other mapping methods}

Other methods can assign genetic markers to chromosomes or chromosomal locations. These generally do not require the target region to be polymorphic, as is required in linkage mapping.

\section{Somatic cell hybrids}

Hybrid cell lines containing chromosomes or chromosomal fragments of the species of interest fused to the genome of another species (usually hamster) can be probed with a gene of interest. Selection of these hybrids can ensure a panel which will enable the gene to be located to a particular chromosome, by observation of which member(s) of the panel it binds to.

In situ hybridization

A gene of interest can be radioactively or fluorescently labelled and allowed to hybridize to metaphase chromosome spreads. The gene can then be assigned to its chromosome, and its position relative to the chromosome banding. 


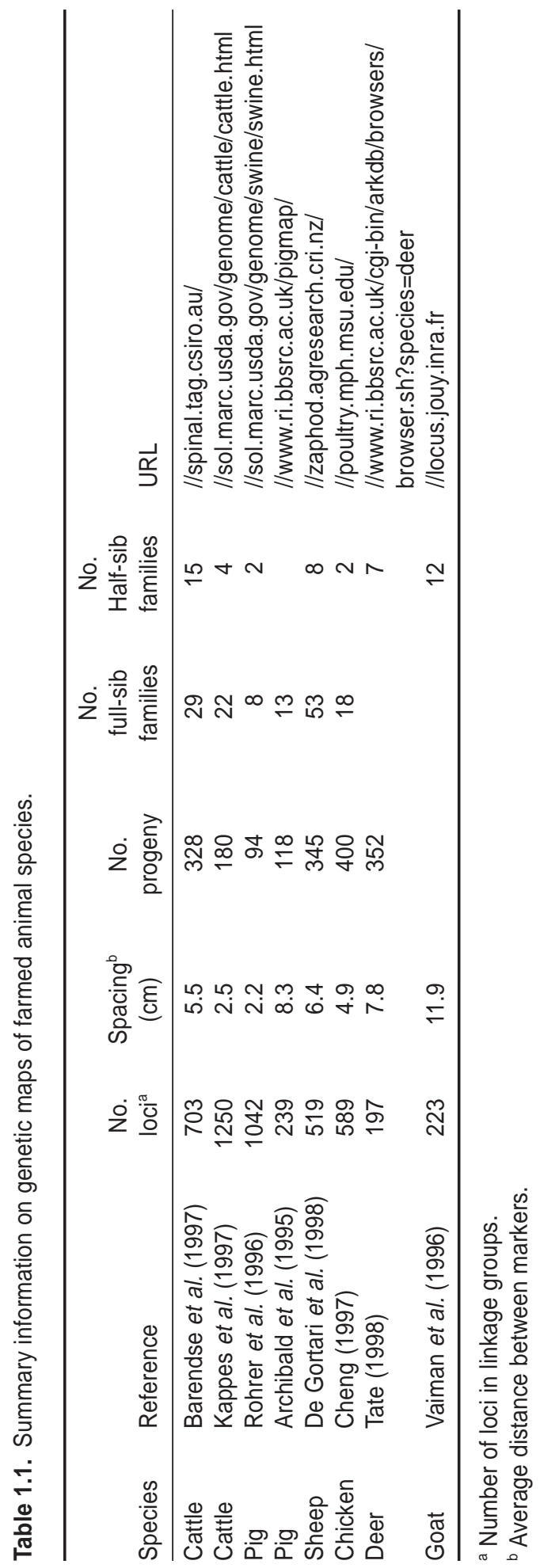


Artificial chromosomes

Genomic DNA can be cut and fragments cloned into a vector such as yeast (to create yeast artificial chromosomes, YACs) or bacteria (to create BACs). A fragment containing a particular genetic marker can be isolated, and this can then be used to isolate fragments that overlap with it. Continuing this process allows contiguous segments to be isolated. These can be used for a variety of purposes, such as developing new markers near an existing marker or searching for gene-coding sequences near a particular marker.

\section{Radiation hybrids}

DNA can be broken into segments by exposing it to radiation. These segments can then be probed with a pair of markers. The proportion of times a fragment contains both markers is then a measure of the distance between the two markers. This proportion also depends on the strength of the radiation, and may make it difficult to compare measures across studies, but has the advantage that different radiation strengths can be applied to obtain different mapping resolutions.

\section{Comparative mapping}

Genetic mapping of a species rarely advances in isolation of maps being developed in other species. There is much conservation of DNA sequences (more so for coding than non-coding sequences) and relative locus position in related species. Some knowledge of the relationships between the genetic maps of different species can aid in the development of their maps.

Comparative mapping data can be obtained in two ways. The first is the comparison of a set of common loci across two or more species. A panel of 410 loci to help in this task has been developed (Lyons et al., 1997). The second is by chromosomal painting - where DNA derived from a chromosome from one species is fluorescently labelled and allowed to hybridize to a chromosome spread of the other species. This identifies the regions corresponding to the target chromosome, providing information at a coarser but more complete level.

Comparative mapping can be used to isolate a gene contributing to phenotypic differences. For example, a comparison of corresponding regions of the human chromosome to that in pigs which contained the locus responsible for the porcine stress syndrome has led to the isolation of the gene responsible (Fujii et al., 1991).

Information from a well-mapped species can direct the mapping effort in a related species. For example, the development of the sheep map has relied heavily on using its relationship to the cattle map to target areas of poor marker density (De Gortari et al., 1998).

Considerable effort may be required to develop polymorphic markers for a locus to be comparatively mapped. One alternative is to use an intermediary species in which it is easier to develop such markers. For example, comparative mapping between ruminants and other species may be most efficient by 
using deer, in which there is an interspecies hybrid mapping population, to establish the relationships with other species (Tate et al., 1995). The relationships within ruminants can then proceed with less well conserved, and usually more polymorphic, regions of DNA.

\section{QTL Detection}

There are many methods to detect QTL affecting multigenic traits such as disease resistance, and these methods have been comprehensively reviewed recently (Lynch and Walsh, 1997). All methods except segregation analysis rely on linkage disequilibrium between the genetic markers described in the first section and the loci affecting the disease trait. While this basic theoretical principle has been known for many years, the explosion of new genetic markers has resulted in rapid development of data analysis techniques to detect QTL. These allow a much wider range of pedigree structures to be utilized. The actual method chosen is determined by several factors, including available knowledge about host factors influencing disease severity, available financial and animal resources, and comparative information of QTL affecting the trait from other species. Often there is no clear distinction between many of the methods and, in practice, several techniques will be required if the ultimate objective is to identify the actual mutation and its effects. The following gives a brief summary of approaches currently being used in farmed animals and describes several recent developments.

\section{Phenotype measurement}

A crucial factor that is often overlooked in any study to identify QTL is the measurement of the disease trait. By their very nature, disease traits are extremely difficult to measure. At the extreme, disease measurement is a binary measurement (affected/not affected), with this classification only crudely reflecting an underlying distribution of susceptibility. Additional complications arise because responses are often affected by the level of challenge, health status of the host and previous exposure to the disease. These problems are also faced by quantitative genetics studies and fortunately, in many cases these researchers have already developed suitable challenge protocols and measurement techniques.

The disease-resistance measurement should ideally be on a continuous scale and highly correlated with actual field resistance. An example of this is the $\gamma$-glutamyl transferase (GGT) levels used to measure facial eczema resistance in sheep (Towers and Stratton, 1978) and faecal egg counts and parasite resistance in sheep (Woolaston et al., 1990). Experimental measurement error should be reduced where possible and additional traits thought to be strongly correlated with the resistance trait should be measured. For example, Crawford et al. (1997a) reported a QTL experiment investigating host resistance to internal parasites where they measured strongyle faecal egg 
counts in three separate samples at the end of each challenge in order to reduce measurement error. Often the cost of genotyping animals is so high that it is cheaper to make multiple phenotypic measurements and so reduce the animal numbers and genotyping required.

Measurement of correlated traits has the benefit that in some cases a QTL may be detected with the correlated trait, but fails to reach significance with the trait of interest. An example of this situation is a study by Comuzzie et al. (1997) where a QTL affecting leptin levels, part of an obesity control feedback loop, was localized to chromosome 2 . In contrast, the primary interest of the study, fat content, while showing the same region to be important, failed to achieve significance. A trait may be affected by several biological control pathways. Multiple measurements of key parameters of these control mechanisms can give an insight into the specific control mechanism for a disease QTL. In the case of disease resistance mediated by the host immune system, measurement of cytokines responsible for Th1 or Th2 immune responses are obvious candidates.

\section{Segregation analysis}

Segregation analyses, designed to detect genetic segregation in the trait of interest in the absence of genotype marker information, have developed rapidly in recent years. Based originally on mixture models and complex segregation analysis (Elston and Stewart, 1971), their current invocation is mixed model inheritance programs FINDGENE (Kinghorn et al., 1993) and Maggic (Janns et al., 1995). The advantage of these new computer algorithms is they can handle large and arbitrary pedigree structures commonly encountered in animal breeding situations. They can screen existing data sets rapidly to identify if large QTL are segregating, their likely mode of inheritance, size of effect and frequency. Their detection limit is a QTL contributing approximately $8 \%$ of the phenotypic variation, which is not as powerful as the linkage disequilibrium techniques discussed later. There are two potential problems for many disease traits: multigenerational pedigrees of disease susceptibility are often not available, and disease-trait measurements are often grossly non-normal. These methods are sensitive to nonnormality and it is often not clear whether the observed non-normality of the disease phenotype is a consequence of segregation or due to extraneous factors.

Despite the problems described above, segregation analyses have already been used to good effect in disease-resistance studies to identify a major gene for tick resistance in cattle (Kerr et al., 1994) and host resistance to internal nematodes in sheep (McEwan and Kerr, 1998). Similar programs have also been used in humans to identify major genes segregating for host resistance to leprosy (Abel and Demenais, 1988), Schistosoma mansoni (Abel et al., 1991) and malaria (Abel et al., 1992). 


\section{Genome scan}

A genome scan consists of genotyping animals, segregating for a QTL affecting the trait of interest, with sufficient markers to detect the QTL. In practice, most experiments limit the search to the autosomes. For outbred species, such as farmed livestock, the magnitude of the resources required for such experiments, often exceeding US $\$ 500,000$, has prompted a large number of publications investigating their optimal design and analysis. Traditionally, genome scans have consisted of rather simple mating designs, in part a result of the difficulties of analysing arbitrary pedigree structures. Currently, three common designs are utilized: outcross, backcross and $\mathrm{F}_{2}$. Backcross and outcross designs are common in sheep and beef cattle experiments because they have fewer resource constraints, but they achieve this at a small expense in power. A variation on the outcross design is the granddaughter design (Weller et al., 1990), where the granddaughters of a large half-sib male progeny group are phenotyped but only the sires and their parents are genotyped. Obviously this structure mimics that of existing dairy evaluation schemes and this is its primary objective.

Typically, for the outcross or backcross design divergent breeds or selection lines for the trait of interest are crossed, and the resulting progeny are mated to a large number of unrelated animals or back to one or both of the parental lines. Generally, the aim is to produce as many progeny per sire as possible. In practice, a minimum of 150 or more progeny are required if the QTL experiment is to have even moderate power. Several half-sib families are generated in order to account for the possibilities that the parental lines also may not be fixed at the QTL and individual sires may not be informative at the markers for a particular region of interest.

The progeny are challenged with the disease and susceptibility is measured. At a minimum, only the sires and the progeny are genotyped, but commonly the grandparents are also genotyped. Dams are usually not genotyped, except for the $\mathrm{F}_{2}$ design, for reasons identical to those discussed in the mapping section. Optimum marker spacing for the initial scan has been investigated by several authors and depends to a small extent on the informativeness of the markers used and their availability at specific chromosome locations. For highly polymorphic, evenly spaced markers, a 20-30 cM spacing is appropriate (Davarsi and Soller, 1994a). Where markers are less polymorphic (e.g. SNPs) or animal numbers are constrained, then a closer spacing may be warranted. An alternative is to use the same method, but in another species more amenable to study. A genomic region conferring tolerance to trypanosomiasis has been identified in mice (Kemp et al., 1996) which, it is hoped, will be useful in finding similar regions in cattle.

\section{Extreme tails}

The large cost of genotyping, currently close to US\$3 per microsatellite genotype, means that many methods have been examined to reduce the number required while still obtaining most of the information. One such method is genotyping only the extreme phenotypic tails of the progeny. This technique 
is particularly suitable for disease traits, because only one trait is of direct interest in the population under study. The exact proportion of progeny to genotype depends on the relative costs of genotyping and phenotyping individuals, but in general somewhere between 15 and 25\% of progeny in each tail is a good compromise (Lander and Botsein, 1989; Darvasi and Soller, 1992). This method was used by Crawford et al. (1997a,b) and Phua et al. (1998) to examine disease traits in farmed livestock. An important implication of this technique is that the magnitude of detected QTL will be overestimated using standard analytical methods.

\section{DNA pooling}

For initial screening, another technique to reduce genotyping costs is to pool the DNA samples from the extreme tails. The sire allele frequencies in the pools are then estimated by densitometry after adjustment using the sire allele densities. Approximate likelihood of the allele frequency differences can be calculated for the particular experiment, and thresholds can be set. This results in a further ten- to 100-fold reduction in the number of genotypes required, albeit at the additional expense of the pool creation and measurement. At a minimum it would only require markers spaced at approximately $20 \mathrm{cM}$ intervals by three samples per sire, or a total of 450 genotypes per half-sib family for a genome length of $3000 \mathrm{cM}$. In practice, however, some replication is desirable. DNA pooling could enable a genomic scan involving four or five sires to be completed by one person in 1 or 2 months. The power of this technique was described theoretically by Darvarsi and Soller (1994b) and Taylor and Phillips (1996) have used the technique to identify QTL in inbred mouse lines using microsatellite markers.

\section{Data analysis}

In recent years there has been an explosion of methods proposed to analyse the data from the experiments described above. The techniques can be divided broadly into two classes, single-marker and multiple-marker methods. In practice, multiple-marker methods have more power than single-marker techniques and all the multiple-marker methods are similar in their detection power, so often other factors will determine the techniques actually used (Bovenhuis et al., 1997; Lynch and Walsh, 1997).

The simplest single-marker technique for outbred species with half-sib outcross or backcross designs is to use regression, nesting the inherited sire allele within the sire. The advantage is that the method can use standard statistical software and is incremental in nature, encouraging its use after each new marker has been completed.

For the designs described previously, two multiple-marker analytical methods are commonly used. The first involves maximum likelihood techniques, and the program ANIMAP (Nielsen et al., 1995) is often utilized for farmed livestock. The second involves the use of regression on the conditional probabilities of the parental phase inherited. This technique was developed independently by Haley and Knott (1992) and Martinez and Curnow (1992).

No matter what technique is used, an extremely important factor in these 
analyses is the calculation of appropriate error thresholds due to the large number of comparisons being made. Lander and Kruglyak (1995) provide a series of graded criteria ranging from suggestive linkage, through to confirmed linkage. The calculation of the appropriate thresholds for a particular experiment can also be undertaken independently using permutation tests where the analysis is replicated many times accompanied by random shuffling of the original data (Churchill and Doerge, 1994).

\section{Fine mapping and candidate genes}

If a QTL has been detected by a method described above, usually the locus is defined only to a 10-30 cM region. Alternative approaches are required to fine map the QTL efficiently. Often the most difficult facet of this technique is to find appropriate polymorphic markers in the region of interest in the putatively segregating sires. Various methods have been used to detect QTL once these markers have been developed.

Candidate-gene techniques differ from genomic scans in that no attempt is made to exclude chromosomal regions using anonymous markers; rather, specific regions are examined using prior knowledge about the disease. Previously, this has largely involved knowledge that a particular host gene was involved in the disease process. However, in the future it will be more common to involve a gene that has been shown previously to be important in other species, or to be located in an important region identified by a prior genomic scan. This exemplifies the key feature of the candidate-gene approach: it is a 'fine mapping' technique and it cannot be used to infer that no QTL exist where no significant results are obtained.

\section{Multiple generations}

Where several intermediate generations of inter-se matings have passed before progeny are evaluated, the linkage disequilibrium between the markers and the linked QTL reduces exponentially in proportion to the map distance separating them. This relationship can be exploited to 'fine map' any QTL identified in an initial scan (Keightley et al., 1996).

This technique is dependent on the animals remaining capable of breeding after evaluation. This will not be possible in many cases involving disease resistance, unless gametes are preserved prior to evaluation. It will also involve excessive time and resources for the majority of farmed livestock if no existing populations are available. One alternative, which uses markedly fewer resources and only one additional generation, is to identify male progeny of a sire segregating for the QTL in which the paternally inherited chromosome has recombined within this interval. If sufficient markers with known map locations are available, animals whose paternal chromosome have recombined at equi-spaced intervals can be selected and progeny tested using an appropriate sized half-sib family. This should be able to restrict the QTL location to a 2-5 cM region, which is sufficiently small to make physical mapping of the region a practical possibility. 


\section{Association}

The most commonly used technique is to examine the association between the candidate gene marker allele and the animal's phenotype. Using these techniques, Gulland et al. (1993) reported an association between host nematode faecal egg count and the ADA locus, located on chromosome 13 of sheep. In a separate study, Stear et al. (1996) found a significant association between host nematode faecal egg count and alleles in the major histocompatibility complex (MHC) region located on chromosome 20. Great care has to be used in these analyses to remove spurious associations, particularly sire effects. Obviously, the designs described for genome scans are ideal for these studies and Phua et al. (1998) have reported results from five candidate loci for facial eczema resistance using such a resource.

\section{Divergent selection lines}

For many farmed livestock, quantitative genetics studies have already produced divergent selection lines from common foundation animals. These flocks are analogous to the multiple-generation fine-mapping resource described previously. As such they are ideal for testing candidate genes, particularly when a region has already been identified from a genome scan experiment using the same experimental population. The basic technique is to measure the selection line allele frequencies of the polymorphism associated with the candidate gene. Appropriate statistical tests are required which take account of founder effects, subsequent genetic drift and sampling effects. Fortunately, accurate pedigree records are also available for many of these flocks, and this allows calculation of the exact probability of the allele frequency difference using simulation (Dodds and McEwan, 1997).

\section{Haplotype analysis}

Once one or several of the above methods has restricted the chromosomal location to a small region, say less than $1 \mathrm{cM}$ or even to within a known gene, alternative methods need to be applied. One method is to develop several markers in the region and consider the various haplotypes (the relevant combination of alleles at all these loci) present in the animals evaluated. Essentially this technique relies on ancestral linkage disequilibrium caused by the QTL mutation occurring on a specific background haplotype. The drawback is that there can be a very large number of haplotypes with correspondingly small numbers in each subgroup. Templeton et al. (1987) suggest that this problem can be overcome by incorporating information of the inferred evolutionary relationships between the sampled haplotypes and then performing nested ANOVAs. Obviously, this method could also be combined with the divergent selection line method detailed in the previous section.

\section{References}

Abel, L. and Demenais, F. (1988) Detection of major genes for susceptibility to leprosy and its subtypes in a Caribbean Island: Desirade Island. American Journal of Human Genetics 42, 256-266. 
Abel, L., Demenais, F., Prata, A., Souza, A.E. and Dessein, A. (1991) Evidence for the segregation of a major gene in human suceptibility/resistance to infection by Schistosoma mansoni. American Journal of Human Genetics 48, 959-970.

Abel, L., Cot, M., Mulder, L., Carnevale, P. and Feingold, J. (1992) Segregation analysis detects a major gene controlling blood infection levels in human malaria. American Journal of Human Genetics 50, 1308-1317.

Archibald, A.L., Haley, C.S., Brown, J.F., Couperwhite, S., McQueen, H.A., Nicholson, D., Coppieters, W., Van de Weghe, A., Stratil, A., Wintero, A.K., Fredholm, M., Larsen, N.J., Nielsen, V.H., Milan, D., Woloszyn, N., Robic, A., Dalens, M., Riquet, J., Gellin, J., Caritez, J.C., Burgaud, G., Ollivier, L., Bidanel, J.P., Vaiman, M., Renard, C., Geldermann, H., Davoli, R., Ruyter, D., Verstege, E.J.M., Groenen, M.A.M., Davies, W., Høyheim, B., Keiserud, A., Andersson, L., Ellegren, H., Johansson, M., Marklund, L., Miller, J.R., Anderson Dear, D.V., Signer, E., Jeffreys, A.J., Moran, C., Le Tissier, P., Muladno, Rothschild, M.F., Tuggle, C.K., Vaske, D., Helm, J., Liu, H.C., Rahman, A., Yu, T.P., Larson, R.G. and Schmitz, C.B. (1995) The PiGMaP consortium linkage map of the pig (Sus scrofa). Mammalian Genome 6, 157-175.

Barendse, W., Vaiman, D., Kemp, S.J., Sugimoto, Y., Armitage, S.M., Williams, J.L., Sun, H.S., Eggen, A., Agaba, M., Aleyasin, S.A., Band, M., Bishop, M.D., Buitkamp, J., Byrne, K., Collins, F., Cooper, L., Coppettiers, W., Denys, B., Drinkwater, R.D., Easterday, K., Elduque, C., Ennis, S., Erhardt, G., Ferretti, L., Flavin, N., Gao, Q., Georges, M., Gurung, R., Harlizius, B., Hawkins, G., Hetzel, J., Hirano, T., Hulme, D., Jorgensen, C., Kessler, M., Kirkpatrick, B.W., Konfortov, B., Kostia, S., Kuhn, C., Lenstra, J.A., Leveziel, H., Lewin, H.A., Leyhe, B., Lil, L., Martin Burrie, I., McGraw, R.A., Miller, J.R., Moody, D.E., Moore, S.S., Nakane, S., Nijman, I.J., Olsaker, I., Pomp, D., Rando, A., Ron, M., Shalom, A., Teale, A.J., Thieven, U., Urquhart, B.G.D., Vage, D.-I., Van de Weghe, A., Varvia, S., Velmala, R., Vilkki, J., Weikard, R., Woodside, C., Womack, J.E., Zanotti, M. and Zaragoza, P. (1997) A medium-density genetic linkage map of the bovine genome. Mammalian Genome 8, 21-28.

Boehnke, M. (1991) Allele frequency estimation from data on relatives. American Journal of Human Genetics 48, 22-25.

Bovenhuis, H., Vanarendonk, J.A.M., Davis, G., Elsen, J.M., Haley, C.S., Hill, W.G., Baret, P.V., Hetzel, D.J.S. and Nicholas, F.W. (1997) Detection and mapping of quantitative trait loci in farm animals. Livestock Production Science 52, 135-144.

Chee, M., Yang, R., Hubbell, E., Berno, A., Huang, X.C., Stern, D., Winkler, J., Lockhart, D.J., Morris, M.S. and Fodor, S.P. (1996) Accessing genetic information with high-density DNA arrays. Science 274, 610-614.

Cheng, H.H. (1997) Mapping the chicken genome. Poultry Science 76, 1101-1107.

Churchill, G.A. and Doerge, R.W. (1994) Empirical threshold values for quantitative trait mapping. Genetics 138, 963-971.

Cockett, N.E., Jackson, S.P., Shay, T.L., Nielsen, D., Moore, S.S., Steele, M.R., Barendse, W., Green, R.D. and Georges, M. (1994) Chromosomal localization of the callipyge gene in sheep (Ovis aries) using bovine DNA markers. Proceedings of the National Academy of Sciences USA 91, 3019-3023.

Comuzzie, A.G., Hixson, J.E., Almasy, L., Mitchell, B.D., Mahaney, M.C., Dyer, T.D., Stern, M.P., MacCluer, J.W. and Blangero, J. (1997) A major quantitative trait locus determining serum leptin levels and fat mass is located on human chromosome 2. Nature Genetics 15, 273-276.

Cooper, D.N., Smith, B.A., Cooke, H.J., Niemann, S. and Schmidtke, J. (1985) An estimate of unique DNA sequence heterozygosity in the human genome. Human Genetics 69, 201-205. 
Crawford, A.M., McEwan, J.C., Dodds, K.G., Bisset, S.A., Macdonald, P.A., Knowler, K.J., Greer, G.J., Green, R.S., Cuthbertson, R.P., Wright, C.S., Vlassoff, A., Squire, D.R., West, C.J., Paterson, K.A. and Phua, S.H. (1997a) Parasite resistance: a genome scan approach to finding markers and genes. Proceedings of the New Zealand Society of Animal Production 57, 297-300.

Crawford, A.M., McEwan, J.C., Dodds, K.G., Wright, C.S., Bisset, S.A., Macdonald, P.A., Knowler, K.J., Greer, G.J., Green, R.S., Shaw, R.J., Paterson, K.A., Cuthbertson, R.P., Vlassoff, A., Squire, D.R., West, C.J. and Phua, S.H. (1997b) Resistance to nematode parasites in sheep: how important are the MHC genes? Proceedings of the Association for the Advancement of Animal Breeding and Genetics 12, 58-62.

Darvasi, A. and Soller, M. (1992) Selective genotyping for determination of linkage between a marker locus and a quantitative trait locus. Theoretical and Applied Genetics 85, 353-359.

Darvasi, A. and Soller, M. (1994a) Optimum spacing of genetic markers for determining linkage between marker loci and quantitative trait loci. Theoretical and Applied Genetics 89, 351-357.

Darvasi, A. and Soller, M. (1994b) Selective DNA pooling for determination of linkage between a molecular marker and a quantitative trait locus. Genetics 138, $1365-1373$.

De Gortari, M.J., Freking, B.A., Cuthbertson, R.P., Kappes, S.M., Keele, J.W., Stone, R.T., Leymaster, K.A., Dodds, K.G., Crawford, A.M. and Beattie, C.W. (1998) A secondgeneration linkage map of the sheep genome. Mammalian Genome 9, 204-209.

Dodds, K.G. and McEwan, J.C. (1997) Calculating exact probabilities of allele frequency differences in divergent selection lines. Proceedings of the Association for the Advancement of Animal Breeding and Genetics 12, 556-560.

Dodds, K.G., Montgomery, G.W. and Tate, M.L. (1993) Testing for linkage between a marker locus and a major gene locus in half-sib families. Journal of Heredity 84, 43-48.

Elsen, J.M., Mangin, B., Goffinet, B. and Chevalet, C. (1994) Optimal structure of protocol designs for building genetic linkage maps in livestock. Theoretical and Applied Genetics 88, 129-134.

Elston, R.C. and Stewart, J. (1971) A general model for the analysis of pedigree data. Human Heredity 21, 523-542.

Fujii, J., Otsu, K., Zorzato, F., de Leon, S., Khanna, V.K., Weiler, J.E., O'Brien, P.J. and MacLennan, D.H. (1991) Identification of a mutation in porcine ryanodine receptor associated with malignant hyperthermia. Science 253, 448-451.

Georges, M., Lathrop, M., Hilbert, P., Marcotte, A., Schwers, A., Swillens, S., Vassart, G. and Hanset, R. (1990) On the use of DNA fingerprints for linkage studies in cattle. Genomics 6, 461-474.

Gulland, F.M.D., Albon, S.D., Pemberton, J.M., Moorcroft, P.R. and Clutton-Brock, T.H. (1993) Parasite-associated polymorphism in a cyclic ungulate population. Proceedings of the Royal Society of London 254, 7-13.

Haley, C.S. and Knott, S.A. (1992) A simple regression method for mapping quantitative trait loci in line crosses using flanking markers. Heredity 69, 315-324.

Hetzel, D.J.S. (1991) The use of reference families for genome mapping in domestic livestock. In: Schook, L.B., Lewin, H.A. and McLaren, D.G. (eds) Gene-mapping Techniques and Applications. Marcel Dekker, New York, pp. 51-64.

Holland, P.M., Abrahamson, R.D., Watson, R. and Gelfand, D.H. (1991) Detection of specific polymerase chain reaction products by utilising the $5^{\prime}$ to $3^{\prime}$ exonuclease activity of Thermus aquaticus DNA polymerase. Proceedings of the National Academy of Sciences USA 88, 7276-7280. 
Janss, L.L.G., Thompson, R. and Van Arendonk, J.A.M. (1995) Application of Gibbs sampling for inference in a mixed major gene-polygenic inheritance model in animal populations. Theoretical and Applied Genetics 91, 1137-1147.

Jeffreys, A.J., Wilson, V. and Thien, S.L. (1985) Hypervariable minisatellite regions in human DNA. Nature 314, 67-73

Kappes, S.M., Keele, J.W., Stone, R.T., McGraw, R.A., Sonstegard, T.S., Smith, T.P.L., Lopez-Corrales, N.L. and Beattie, C.W. (1997) A second-generation linkage map of the bovine genome. Genome Research 7, 235-249.

Keightley, P.D., Hardge, T., May, L. and Bulfield, G. (1996) A genetic map of quantitative trait loci for body weight in the mouse. Genetics 142, 227-235.

Kemp, S.J., Darvasi, A., Soller, M., Teale, A.J., Shewen, P.E., Lunney, J.K. and Gershwin, L.J. (1996) Genetic control of resistance to trypanosomiasis. Veterinary Immunology and Immunopathology 54, 239-243.

Kerr, R.J., Frisch, J.E. and Kinghorn, B.P. (1994) Evidence for a major gene for tick resistance in cattle. Proceedings 5th World Congress on Genetics Applied to Livestock Production 20, 265-268.

Kinghorn, B.P., Kennedy, B.W. and Smith, C. (1993) A method of screening for genes of major effect. Genetics 134, 351-360.

Lander, E.S. and Botstein, D. (1989) Mapping Mendelian factors underlying quantitative traits using RFLP linkage maps. Genetics 121, 185-199.

Lander, E.S. and Green, P. (1987) Construction of multilocus genetic linkage maps in humans. Proceedings of the National Academy of Sciences USA 84, 2363-2367.

Lander, E. and Kruglyak, L. (1995) Genetic dissection of complex traits: guidelines for interpreting and reporting linkage results. Nature Genetics 11, 241-247.

Lander, E.S., Green, P., Abrahamson, J., Barlow, A., Daly, M.J., Lincoln, S.E. and Newburg, L. (1987) MAPMAKER: an interactive computer package for constructing primary genetic linkage maps of experimental and natural populations. Genomics 1, $174-181$.

Lange, K., Weeks, D. and Boehnke, M.. (1988) Programs for pedigree analysis: MENDEL, FISHER and dGENE. Genetic Epidemiology 5, 471-472.

Lathrop, G.M., Lalouel, J.M., Julier, C. and Ott, J. (1984) Strategies for multilocus analysis in humans. Proceedings of the National Academy of Sciences USA 81, 3443-3446.

Lynch, M. and Walsh, B. (1997) Genetics and Analysis of Quantitative Traits. Sinauer Associates, Massachusetts.

Lyons, L.A., Laughlin, T.F., Copeland, N.G., Jenkins, N.A., Womack, J.E. and O'Brien, S.J. (1997) Comparative anchor tagged sequences (CATS) for integrative mapping of mammalian genomes. Nature Genetics 15, 47-56.

McEwan, J.C. and Kerr, R.J. (1998) Further evidence that major genes affect host resistance to nematode parasites in Coopworth sheep. Proceedings of the 6th World Congress of Genetics Applied to Livestock Production 27, 335-338.

Martinez, O. and Curnow R.N. (1992) Estimating the locations and the sizes of the effects of quantitative trait loci using flanking markers. Theoretical and Applied Genetics $85,480-488$.

Meuwissen, T.H.E. and Goddard, M.E. (1996) The use of marker haplotypes in animal breeding schemes. Genetics, Selection, Evolution 28, 161-176.

Montgomery, G.W., Penty, J.M., Henry, H.M., Sise, J.A., Lord, E.A., Dodds, K.G. and Hill D.F. (1995) Sheep linkage mapping: RFLP markers for comparative mapping studies. Animal Genetics 26, 249-259

Nielsen, D., Cockett, N.E. and Georges, M. (1995) Mapping markers and quantitative 
traits in large half-sib pedigrees. Proceedings of the Western Section of the American Society of Animal Science 46, 205-208.

Orita, M., Iwahana, H., Kanazawa, H., Hayashi, K. and Sekiya T. (1989) Detection of polymorphisms of human DNA by gel electrophoresis as single-strand conformation polymorphisms. Proceedings of the National Academy of Sciences USA 86, 2766-2770.

Ott, J. (1991) Analysis of Human Genetic Linkage. Johns Hopkins University Press, Baltimore.

Phua, S.H., Dodds, K.G., Morris, C.A., Towers, N.R. and Crawford, A.M. (1998) Antioxidant enzymes as candidate genes for disease resistance in sheep facial eczema. Proceedings of the 6th World Congress of Genetics Applied to Livestock Production 27, 273-276.

Rohrer, G.A., Alexander, L.J., Hu, Z.L., Smith, T.P.L., Keele, J.W. and Beattie, C.W. (1996) A comprehensive map of the porcine genome. Genome Research 6, 371-391.

Sambrook, J., Fritsch, E.F. and Maniatis, T. (1989) Molecular Cloning: a Laboratory Manual. 2nd Edn. Cold Spring Harbor Laboratory Press, Cold Spring Harbor, New York.

Stear, M.J., Bairden, K., Bishop, S.C., Buitkamp, J., Epplen, J.T., Gostomski, D., McKellar, Q.A., Schwaiger, F.W. and Wallace, D.S. (1996) An ovine lymphocyte antigen is associated with reduced faecal egg counts in four-month-old lambs following natural, predominantly Ostertagia circumcincta infection. International Journal for Parasitology 26, 423-428.

Tate, M.L. (1998) Evolution of ruminant chromosomes. PhD thesis, University of Otago, Dunedin, New Zealand.

Tate, M.L., Mathias, H.C., Fennessy, P.F., Dodds, K.G., Penty, J.M. and Hill, D.F. (1995) A new gene mapping resource: interspecies hybrids between Père David's deer (Elaphurus davidianus) and red deer (Cervus elaphus). Genetics 139, 1383-1391.

Taylor, B.A. and Phillips, S.J. (1996) Detection of obesity QTLs on mouse chromosomes 1 and 7 by selective DNA pooling. Genomics 34, 389-398.

Templeton, A.R., Boerwinkle, E. and Sing, C.F. (1987) A cladistic analysis of phenotypic associations with haplotypes inferred from restriction endonuclease mapping. I. Basic theory and an analysis of alcohol dehydrogenase activity in Drosophila. Genetics 117, 343-351.

Towers, N.R. and Stratton, G.C. (1978) Serum gamma-glutamyltransferase as a measure of sporidesmin-induced liver damage in sheep. New Zealand Veterinary Journal 26, 109-112.

Vaiman, D., Schibler, L., Bourgeois, F., Oustry, A., Amigues, Y. and Cribiu, E. (1996) A genetic linkage map of the male goat genome. Genetics 144, 279-305.

van der Beek, S. and van Arendonk, J.A.M. (1993) Criteria to optimize designs for detection and estimation of linkage between marker loci from segregating populations containing several families. Theoretical and Applied Genetics 86, 269-280.

Vos, P., Hogers, R., Bleeker, M., Reijans, M., van de Lee, T., Hornes, M., Frijters, A., Pot, J., Peleman, J., Kuiper, M. and Zabeau, M. (1995) AFLP: a new technique for DNA fingerprinting. Nucleic Acids Research 23, 4407-4414.

Weller, J.I., Kashi, Y. and Soller, M. (1990) Power of daughter and granddaughter designs for determining linkage between marker loci and quantitative trait loci in dairy cattle. Journal of Dairy Science 73, 2525-2537.

Williams, J.G., Kubelik, A.R., Livak, K.J., Rafalski, J.A. and Tingey, S.V. (1990) DNA polymorphisms amplified by arbitrary primers are useful as genetic markers. Nucleic Acids Research 18, 6531-6535.

Woolaston, R.R., Barger, I.A. and Piper, L.R. (1990) Response to Helminth infection of 
sheep selected for resistance to Haemonchus contortus. International Journal for Parasitology 20, 1015-1018.

Zhu, K.Y. and Clarke, J.M. (1996) Addition of a competitive primer can dramatically improve the specificity of PCR amplification of specific alleles. Biotechniques 21, 586-587. 